\title{
Stereotactic Surgery Frame Type
}

National Cancer Institute

\section{Source}

National Cancer Institute. Stereotactic Surgery Frame Type. NCI Thesaurus. Code C106570.

The type or classification of the cage structure used to immobilize the head or other body part in preparation for stereotactic surgery. 